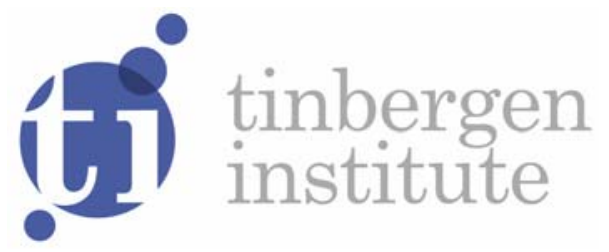

\title{
Damming Trans-boundary Rivers: A Welfare Analysis of Conflict and Cooperation
}

Yuyu Zeng ${ }^{1}$

Harold Houba'

Ariel Dinar ${ }^{2}$

Miroslav Marence 3

' Faculty of Economics and Business Administration, VU University Amsterdam, and Tinbergen Institute, The Netherlands;

2 University of California, Riverside, United States;

3 UNESCO-IHE Institute for Water Education, The Netherlands. 
Tinbergen Institute is the graduate school and research institute in economics of Erasmus University Rotterdam, the University of Amsterdam and VU University Amsterdam.

More TI discussion papers can be downloaded at http://www.tinbergen.nl

Tinbergen Institute has two locations:

Tinbergen Institute Amsterdam

Gustav Mahlerplein 117

1082 MS Amsterdam

The Netherlands

Tel.: +31(0)20525 1600

Tinbergen Institute Rotterdam

Burg. Oudlaan 50

3062 PA Rotterdam

The Netherlands

Tel.: +31(0)10 4088900

Fax: +31(0)10 4089031 


\title{
Damming Trans-boundary Rivers: a Welfare Analysis
}

\section{of Conflict and Cooperation*}

\author{
Yuyu Zeng ${ }^{1}$, Harold Houba ${ }^{1}$, Ariel Dinar ${ }^{2}$, and Miroslav Marence ${ }^{3}$ \\ ${ }^{1}$ Department of Econometrics, Vrije Universiteit Amsterdam and \\ Tinbergen Institute, the Netherlands \\ ${ }^{2}$ School of Public Policy, University of California, Riverside, USA \\ ${ }^{3}$ Department of Water Engineering, UNESCO-IHE Institute for Water \\ Education, the Netherlands
}

October 24, 2016

\footnotetext{
${ }^{*}$ This research is financially supported by Netherlands Organization for Scientific Research NWO grant 022.003.025. Part of the research is conducted during the first author's visit at the School of Public Policy, University of California, Riverside and the financial support from C. Willems Stichting Grant for this visit is appreciated. We have also benefited from intensive discussions with Gerard van der Laan. Valuable suggestions from seminar participants at the Vrije Universiteit Amsterdam, Tinbergen Institute Amsterdam, the University of Groningen and the Hebrew University of Jerusalem are also appreciated. The views expressed in this paper are those of the authors and should not be attributed to their respective institutions. Corresponding author: Yuyu Zeng, yuyu.zeng1@gmail.com, tel: +31 634826978, fax: +31205986020 .
} 
Damming Trans-boundary Rivers: a Welfare Analysis of Conflict and Cooperation

\begin{abstract}
Dams are essential for water storage and hydropower generation, but change river flow patterns and endanger local environments. Dam projects may further exacerbate already existing problems in trans-boundary rivers. We consider three scenarios of institutional factors: (1) each country pursues its own interests, (2) efficient cooperation along the river and (3) partial cooperation among neighboring countries. We conduct cost-benefit analyses for these scenarios incorporating dam projects and their externalities. We demonstrate our approach for the Mekong River incorporating expert hydrological knowledge regarding installed hydropower capacity and dam location instead of the standard economic assumptions of such costs. Our results show that cooperation between Laos and Cambodia internalizes the negative impacts of dam construction in Laos on fishery in Cambodia, and Laos refrains from building some planned dams. Our results also hint that the 1995 Mekong Agreement among Thailand, Laos, Cambodia and Vietnam is internally stable.
\end{abstract}

Keywords: Trans-boundary river basin management, Institutional factors, Dams, Externalities, Welfare analysis, Conflict and cooperation

\title{
1 Introduction
}

Dams are constructed to deal with seasonal variations of river water flows within a year. They play a role in storing water from the wet to the dry season and generating hydropower. For example, that the Grand Millennium Dam under construction in Ethiopia, on the Blue Nile River, is built mainly for hydropower generation and water storage (Gebreluel, 2014; Jueland and Whittington, 2014). On the other hand, dams alter river flows and might have negative impacts on livelihoods and the environment. For instance, there is a number of studies concerning the impact of dams on fishery in the Mekong River Basin since dams hinder the many migratory fish species in the river (Baron et al., 2007; ICEM, 2010; the Economist, (2016)); the Grand Millennium Dam on the Nile River 
in upstream Ethiopia may significantly change the river flow pattern and endanger the livelihoods in downstream Egypt (Gebreluel, 2014; Jueland and Whittington, 2014).

The impact of a dam might not be confined to regimes within a country but also be trans-boundary in nature. Unfortunately, there is no government structure to resolve the disputes over trans-boundary river basins, and conflicts in international river basins are well documented (Just and Netanyahu, 1998; Dinar and Dinar, 2003). For instance, an upstream country can divert water at its source or pollute water carelessly, decreasing both water quantity and quality available to downstream countries. The introduction of dam projects in trans-boundary river basins further exacerbates existing disputes regarding water allocation and pollution by adding dam externalities. Olmstead and Sigman (2014: 2) state that "As the main mechanism for diverting water from rivers, dams also pose an important common property problem that has not been addressed in the literature."

This paper explicitly addresses the externalities of dam projects in a trans-boundary river setting. We first derive a complete and flexible cost-benefit economic model that integrates dam projects and externalities of dam projects. The Mekong River Basin fits well in this framework with 12 proposed mainstream dams for hydropower generation, which create negative impacts on fishery and salinity of water flows. This means that the Mekong River Basin is suited as a case study to demonstrate the application of our approach. We believe that our approach is rather general and could be easily accommodated for a study of other river basins.

Institutional factors in trans-boundary river basin management have been recognized by water researchers. Dinar et al. (2015) explore treaty effectiveness, or treaty resilience, by investigating whether particular water allocation and institutional mechanisms help mitigate inter-country tensions over shared water. They conclude that treaties containing enforcement, monitoring, conflict resolution, joint commission, adaptability mechanisms to water variability, and self-enforcement mechanisms (e.g., side-payments, benefitsharing and issue-linkage), are likely to witness heightened cooperation. Houba et al. (2013) consider strong and weak governance of the 1995 Mekong Agreement regarding 
the long-term sustainable development of the Lower Mekong River Basin. In the weak governance model, dam operators and agricultural users in this region optimize their own benefits without internalizing any regional externalities at all. These regional externalities will be internalized in the strong governance model.

Our study of institutional factors' impact on trans-boundary river basin management includes two layers. The first layer considers whether or not there are institutions in place to manage trans-boundary water. If so, the institution could be basin-wide or applicable only to part of the basin. The second layer considers the effectiveness of the institution and we define strong and weak governance versions of institutions correspondingly.

In case of no institution or weak governance of an institution, we refer to a scenario where each country pursues their own interest. This scenario is also supported by the principle of Absolute Territorial Sovereignty (hereafter, ATS) taken from International Water Law, which is also known as the Harmon Doctrine. This principle states that a country has absolute sovereignty over the area of any river basin on its territory: it may freely decide how much water to use of the water flowing within its borders but cannot claim the continued and uninterrupted flow from upper basin countries. This scenario provides each country their fallback option in a state of "laissez-faire". In this paper, we name this scenario the disagreement scenario.

Basin-wide cooperate requires that there exists a basin-wide institution and such institution can enforce strong governance. The 1997 United Nations Report states that, "there is a clear need for cooperation in the management of international and trans-boundary watercourses to maximize mutual benefits for all riparian countries." The mutual gains from cooperation may also lure all countries to cooperate. When there are mutual gains, there exist many possibilities to satisfy each country in their benefits distribution. In this paper, we call this scenario the joint cooperation scenario.

Though joint cooperation delivers maximum benefits in almost all cases, Just and Netanyahu (1998) identify several difficulties for basin-wide cooperation, such as natural claims for sovereignty, unavoidable conflicting national and international interests, and geographical upstream or downstream considerations. Indeed, basin-wide agreements on 
water allocation are rarely formed for basins with a large number of riparians. Instead, agreements involving subsets of countries are often observed. For example, four Lower Mekong countries (i.e., Laos, Thailand, Cambodia and Vietnam) signed the 1995 Mekong Agreement to manage the water allocation in the Lower Mekong Region and upstream China is not in the agreement. ${ }^{1}$ In this paper, we name this scenario the partial cooperation scenario. Our partial cooperation scenario refers to a strong governance version of the agreement and absence of cooperation with non-member countries.

To our best knowledge, this paper also serves as the first paper using field data to study the internal stability of international environmental agreements in the context of river basins. In the agenda of studies in international environmental agreement, the internal stability of an agreement has been extensively discussed as in d'Aspremont et al. (1983), Eyckmans and Finus (2004), Weikard (2009), Weikard et al. (2006) and Heijnen and Dam (2015). A key issue among these studies is that due to heterogeneity of all countries, each country might have a different outside option when they consider leaving the current agreement. Parametric examples are very well developed in the above mentioned studies to investigate internal stability of an international environmental agreement and support the rather dismal result that international cooperation is limited to coalitions of small size. This question is also vital in analyzing already established treaties to prevent existing members from unilaterally defecting in river basins, where the unidirectional flow of the river adds an additional dimension.

Studies regarding damming in a trans-boundary river basin are rather rare. ?) estimate econometric models of the location of major dams around the world as a function of the degree of international sharing of rivers. Their major findings are dams are more prevalent in areas of river basins upstream of foreign countries. These results support the view that countries free ride in exploiting water resources as in Sigman (2002). Our paper focuses on numerical optimization regarding feasible dam plans taking other water use sectors (e.g., agriculture, fishery, industry, etc.) into account.

\footnotetext{
${ }^{1}$ Though Myanmar is in the Mekong river basin, it accounts for about only 2 percent of the flow and 3 percent of the catchment area of the whole basin. In addition, Myanmar pursues a separatist policy and was not involved in any basin negotiations over the past decades.
} 
The papers that are closest to ours are Haddad (2011) and Houba et al. (2013). Houba et al. (2013) consider the cost of dam construction as a convex function of dam capacity. The form of the cost function matters. For example, by assuming convex construction costs of capacity, the decision regarding dam construction tends to have many small dams instead of one big dam, ceteris paribus. This contrasts the reality that big dams prevail due to the concavity of the costs. In our model, we only assume that the costs of dam construction are increasing in dam capacity. On the other hand, hydrological experts calculate dam construction costs from installed capacities (IRENA, 2012). Haddad (2011) and Houba et al. (2013) address the reservoir dam capacities given the available water inflow. However, their model could not provide further information regarding the location of the dams. In our application to the Mekong River Basin in Section 5, we use the data regarding location of dams and installed capacities obtained from engineers and incorporate such information in our cost-benefit analysis. When determining the location and size of dams, engineers already take geographical factors and water flow information at the dam location into account. Therefore, our empirical study regarding the Mekong River Basin focuses on evaluating the costs and benefits for dam construction and also how the externalities of dam projects will be addressed under different scenarios arising from exogenous institutional factors.

The remainder of this paper is organized as follows. Section 2 defines the transboundary river basin model taking damming and its externalities into account. In Section 3, the disagreement and the joint cooperation scenarios are analyzed. The model with partial cooperation scenario is presented in Section 4. We apply the model to investigate the Mekong River Basin in Section 5. Section 6 concludes.

\section{The model}

Let $N=\{1,2, \cdots, n\}$ be the set of agents involved in the river sharing problem. An agent should be interpreted as a water use spot, e.g., a country, a region or a city. Following Houba et al. (2014b), we denote $P^{i}$ as the set of all agents that can possibly transfer 


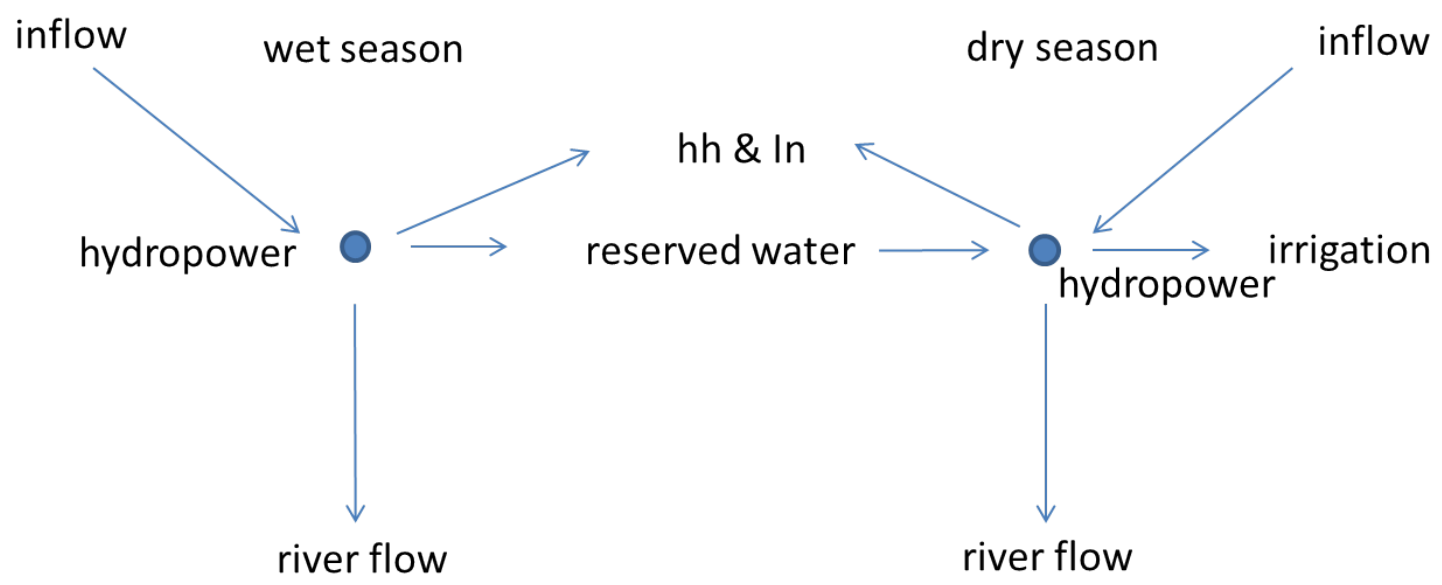

Figure 1: Water allocation within the water economy of an agent

water to agent $i, i \in N$. We consider rivers that arise in multiple springs, but we do not consider situations where rivers diverge. ${ }^{2}$ We sketch the scenario of water allocation within agent $i$ 's territory in Figure 1 . Within a year, economic activities related to water can be classified being at the wet or dry seasons. We denote $s \in S=\{w, d\}$ for the wet or dry seasons. Each agent $i$ receives inflow $o_{i, s}$ from their predecessors in season $s$ and the amount of water resources arising in agent $i$ 's territory is denoted as $e_{i, s}$. The inflow for agent $i$ in Figure 1 should be interpreted as the sum of inflows received from their predecessors plus the water resource arising within agent $i$. Dams play an important role in storing water from the wet to dry season, but not across years. Hence, our model only includes wet and dry seasons within a year, but do not consider water reservation across years. The water stored behind the dam is constrained by the dam capacity $D_{i}$ and can be used for hydropower generation, household and industry, and irrigation consumption. ${ }^{3}$ The water reserved from the wet to dry season for agent $i$ is denoted as $r_{i}$. Water use can be further classified as in-stream and off-stream use. In-stream use means that water used upstream can be re-used further downstream, e.g., the water use for hydropower generation. In case that water use is consumptive, ${ }^{4}$ we say that it is off-stream use, e.g.,

\footnotetext{
${ }^{2}$ In case where the river diverges at a certain point, we need additional information, e.g., water flow and altitude difference at the divergence location, to identify the water flow amount to each branch.

${ }^{3}$ Strictly speaking, the dam capacity here refers to the capacity of the dam reservoir as in Haddad (2011).

${ }^{4}$ As stated in Pham Do and Dinar (2014: 501), "consumptive use commonly refers to water that is unavailable for reuse in the basin from which it was extracted due to evaporation, incorporation into production biomass, transfer to another basin, seepage to saline sink, or contamination."
} 
household, industry and irrigation. Hence, the return flow from off-stream use is 0 in this paper. We assume that there is no seasonal differences in household and industry water related activities, thus they take the same benefit function across seasons. We assume a benefit function $b_{i, k}\left(x_{i, k, s}\right)$ for off-stream water use of agent $i$ in season $s$ and sectors $k \in K=\{h h, i n, i r\}$ could be household, industry and irrigation, where $x_{i, k, s}$ is the water use amount in agent $i$ in season $s$ of sector $k$.

Assumption 2.1. The benefit function $b_{i, k}\left(x_{i, k, s}\right): \mathbb{R}_{+} \rightarrow \mathbb{R}_{+}, i \in N, s \in S, k \in K$, is continuous, differentiable, strictly concave and has a satiation point $\hat{x}_{i, k, s}$, with $\hat{x}_{i, i r, w}=0$.

The latter assumption states that there is no irrigation taking place in the wet season.

Assumption 2.2. The cost function of dam construction $c_{i}\left(D_{i}\right): \mathbb{R}_{+} \rightarrow \mathbb{R}_{+}, i \in N$, is continuous, differentiable and increasing, i.e., $\frac{\partial c_{i}}{\partial D_{i}}>0$.

The seasonal water use for hydropower generation within the territory of each agent $i$ is denoted by $q_{i, s}$ and the benefit function from seasonal water use for hydropower generation is $Q_{i}\left(q_{i, s}\right)$. Given the dam $i$ 's height, $Q_{i}\left(q_{i, s}\right)$ is independent of seasons according to the physical laws.

Assumption 2.3. The benefit function from hydropower generation is continuous, nondecreasing in the amount of water use for hydropower generation. And there exists a $\hat{q}_{i, s}>0$ such that for $q_{i, s} \in\left[0, \hat{q}_{i, s}\right], \frac{\partial Q_{i}}{\partial q_{i, s}}>0$ and for $q_{i, s}>\hat{q}_{i, s}, \frac{\partial Q_{i}}{\partial q_{i, s}}=0, i \in N, s \in S$.

In the above assumption, we allow for the possibility that $\frac{\partial Q_{i}}{\partial q_{i, s}}=0$ by taking the maximum capacity of turbines of hydropower generation into account.

We have a damage function for agent $i$ when dams in agent $i$ 's territory or their predecessors are built. Note that we allow damage to agent $i$ incurring by the dams from their predecessors. The damage function can be interpreted as environmental and ecological costs, e.g., damage to fishery in downstream Cambodia due to dam construction in upstream Laos in the Mekong River Basin (Baron et al., 2007; ICEM, 2010). Let $\tilde{\mathbf{D}}_{\mathbf{i}} \in \chi_{h \in P^{i} \cup\{i\}} D_{h}$ and $F_{i}\left(\tilde{\mathbf{D}}_{\mathbf{i}}\right)$ be the annual damage function for agent $i$. 
Assumption 2.4. Refraining from building dams on agent i's territory and their predecessors does not cause damages to agent $i$, i.e., $F_{i}(0, \cdots, 0)=0$. The marginal damage of building dams on agent $h$ 's territory, $h \in P^{i} \cup\{i\}$ is nonnegative for agent $i$, i.e.,

$$
\frac{\partial F_{i}}{\partial D_{h}} \geq 0
$$

Given inflows $o_{i, w}$ and $o_{i, d}$ received from their predecessors in the wet and dry seasons, we have the following maximization problem for agent $i$,

$$
\begin{aligned}
\max _{x_{i, k, s}, q_{i, s}, D_{i}} & \sum_{k \in K} \sum_{s \in S} b_{i, k}\left(x_{i, k, s}\right)+\sum_{s \in S} Q_{i}\left(q_{i, s}\right)-c_{i}\left(D_{i}\right)-F_{i}\left(\tilde{\mathbf{D}}_{\mathbf{i}}\right) \\
\text { s.t. } \quad & \sum_{k \in K} x_{i, k, w}+q_{i, w}+r_{i} \leq e_{i, w}+o_{i, w}, \\
& \sum_{k \in K} x_{i, k, d}+q_{i, d} \leq e_{i, d}+o_{i, d}+r_{i}, \\
& \sum_{k \in K} x_{i, k, w}+q_{i, w}+r_{i} \leq D_{i},
\end{aligned}
$$

where

$$
o_{i, w}=\sum_{h \in P^{i}}\left(e_{h, w}-r_{h}-\sum_{k \in K} x_{h, k, w}\right)
$$

is the water resources agent $i$ receives from their predecessors in the wet season and

$$
o_{i, d}=\sum_{h \in P^{i}}\left(e_{h, d}+r_{h}-\sum_{k \in K} x_{h, k, d}\right)
$$

is the water resources agent $i$ receives from their predecessors in the dry season. The objective function (1) summarizes agent $i$ 's water use benefits derived from corresponding sectors (household, industry, irrigation and hydropower), the costs for dam construction and negative externalities from dam construction of this agent and their predecessors. The water resource constraint for agent $i$ in the wet season is given by (2) and this agent's constraint in the dry season is given by (3). Note that $r_{i}$ is stored in the wet season for use in the dry season. The water storage behind the dam should not exceed 
the capacity as stated in (4) and it can be used for consumptive use in any sector $k$, hydropower generation and water reservations. We only add the water storage constraint in the wet season since we assume that in most cases the storage capacity behind the dam is more limiting in the wet season than the dry season.

\section{The disagreement and joint cooperation scenarios}

In this section, we discuss the application of the Absolute Territorial Sovereignty principle to the disagreement scenario and how to calculate the maximal benefits and distribute the benefits among all agents in the joint cooperation scenario by applying the asymmetric Nash bargaining solution. Similar analysis can be found in Houba et al. (2014b).

In trans-boundary river basins, the property rights for water are not properly defined. Two principles are invoked in most situations, i.e., Absolute Territorial Sovereignty (ATS) and Unlimited Territorial Integrity (UTI) (Ambec and Sprumont, 2002; McCaffrey, 2001). The ATS principle describes the scenario of either no institution or weak governance of an institution. Based on this principle, we calculate each agent's disagreement point and denote the corresponding result as $\mathbf{d}=\left(d_{1}, d_{2}, \cdots, d_{n}\right) \in \mathbb{R}_{+}^{n}$. Similar to Houba et al. (2014b), we use the following algorithm to calculate the disagreement point $\mathbf{d}$, applied to a more comprehensive situation,

1. We start with any agent that does not have any predecessors, i.e., $P^{i}=\emptyset$. For agent $i$ with $P^{i}=\emptyset, o_{i, s}=0, s=w, d$. Then we solve the maximization problem (1)-(4) for agent $i$ and $d_{i}$ is the value of (1) in the solution.

2. For agent $i$, in case that their predecessors' disagreement points are calculated, $o_{i, s}$ follows from equations (5) and (6). Then we solve the maximization problem (1)-(4) for agent $i$.

Note that for each agent $i$, we will be able to calculate the disagreement point as illustrated in Step 2 in the above algorithm conditional on that their predecessors' optimal disagreement points are settled and are common knowledge. We denote the solution of 
(1)-(4) for $i \in N$ as $\left\{x_{i, k, s}^{*}, q_{i, s}^{*}, D_{i}^{*}\right\}$. Subsequently, we can obtain the disagreement vector $d^{*}$ by plugging the above solution into (1). It is quite straightforward to prove the existence of $\left\{x_{i, k, s}^{*}, q_{i, s}^{*}, D_{i}^{*}\right\}, i \in N$, by applying the Weierstrass Extreme Value Theorem.

In the above algorithm, we have solved the disagreement scenario by applying the ATS principle. Next, we are going to consider the joint cooperation scenario. In the trans-boundary river sharing problem, given each agent's disagreement point, applying the (asymmetric) Nash bargaining solutions to solve the joint cooperation scenario is a good option taking efficiency and fairness into account (Nash, 1950; Binmore et al., 1986; Houba et al., 2014b). Nash bargaining solutions achieve the maximal amount of benefits in the whole river basin and distribute the benefits among all agents based on the disagreement point and the bargaining weights. The bargaining weights of the agents, given by $\alpha=\left(\alpha_{1}, \alpha_{2}, \cdots, \alpha_{n}\right) \in \mathbb{R}_{+}^{n}$, with $\sum_{i=1}^{n} \alpha_{i}=1$, are assumed to be exogenously determined by GDP, population sizes, political factors, military strength and other factors, see also Dinar et al. (2015: 58-60). There are two elements to be considered for the final outcome in the asymmetric Nash solutions: the disagreement vector $\mathbf{d}$ and the maximal benefits from cooperation. Let $v$ be the value of the objective function in a solution of the following maximization problem,

$$
\begin{gathered}
\max _{x_{i, k, s}, q_{i, s}, D_{i}} \sum_{i \in N}\left(\sum_{k \in K} \sum_{s \in S} b_{i, k}\left(x_{i, k, s}\right)+\sum_{s \in S} Q_{i}\left(q_{i, s}\right)-c_{i}\left(D_{i}\right)-F_{i}\left(\tilde{\mathbf{D}}_{\mathbf{i}}\right)\right) \\
\text { s.t. } \quad \sum_{k \in K} x_{i, k, w}+q_{i, w}+r_{i} \leq e_{i, w}+o_{i, w}, i=1, \cdots, n, \\
\sum_{k \in K} x_{i, k, d}+q_{i, d} \leq e_{i, d}+o_{i, d}+r_{i}, i=1, \cdots, n, \\
\sum_{k \in K} x_{i, k, w}+q_{i, w}+r_{i} \leq D_{i}, i=1, \cdots, n, \\
o_{i, w}=\sum_{h \in P^{i}}\left(e_{h, w}-r_{h}-\sum_{k \in K} x_{h, k, w}\right), i=1, \cdots, n, \\
o_{i, d}=\sum_{h \in P^{i}}\left(e_{h, d}+r_{h}-\sum_{k \in K} x_{h, k, d}\right), i=1, \cdots, n .
\end{gathered}
$$

Let $\left\{\hat{x}_{i, k, s}, \hat{q}_{i, s}, \hat{D}_{i}\right\}, i \in N$, be a solution of the maximization problem (7). It can be 
easily verified that $\sum_{i} d_{i} \leq v$ since the solution of the maximization (1)-(4) for all agents is an admissible choice for maximization problem (7).

In the joint cooperation scenario in which all agents involved cooperate, let $u_{i}$ be the final outcome for agent $i, i \in N$. Application of the (asymmetric) Nash bargaining solution (Houba et al., 2014b) yields the following result.

Proposition 3.1. In the joint cooperation scenario, each agent gets its disagreement payoff plus a share of the surplus, i.e.,

$$
u_{i}=d_{i}+\alpha_{i}\left(v-\sum_{i} d_{i}\right), i \in N
$$

The final outcome for agent $i$ under joint cooperation is obtained by applying the asymmetric Nash bargaining solution with total payoffs $v$, disagreement payoff $d_{i}$ and their bargaining weight $\alpha_{i}$. Each agent $i$ gets their disagreement payoff $d_{i}$ plus their fractional share (which is defined by their bargaining power $\alpha_{i}$ ) of the surplus $v-\sum_{i} d_{i}$.

\section{Partial cooperation scenario}

In this section, we discuss the partial cooperation scenario and also the concept of internal stability of an already formed agreement. In trans-boundary river basins, most partial cooperation involves countries that are geographically contiguous, for instance, the 1995 Mekong Agreement and the Nile Cooperative Frame Agreement in 2010 as mentioned in the introduction and the 1998 Bishkek Water Agreement signed by Kyrgyzstan, Uzbekistan and Kazakhstan on the Syr Darya River. Let $\Pi$ be the collection of all possible partitions of $N$. We denote an exogenous partition of $N$ into $m$ connected groups of agents as $\pi=\left\{P_{1}, P_{2}, \ldots, P_{m}\right\} \in \Pi$ and we call an element in $\pi$ a group of agents that sign an international water agreement. In particular, each connected $P_{j}$ has a unique most downstream agent $p_{j}^{d}$ and each $h \in P_{j}$ is connected to $p_{j}^{d}$ within $P_{j} \cdot{ }^{5}$ Note that $\left|P_{1}\right|+\left|P_{2}\right|+\cdots+\left|P_{m}\right|=n, m \leq n$, where $\left|P_{j}\right|, j=1, \ldots, m$, is the number of agents

\footnotetext{
${ }^{5}$ In terms of graph theory, there exists a path between two agents within any connected group of agents.
} 
in $P_{j}, P_{j} \in \pi$. In case that $m=n$, each agent is a singleton and the situation is degenerated into the disagreement scenario discussed in Section 3. In case that $m=1$, the grand coalition is formed and the situation is the joint cooperation scenario discussed in Section 3. Let the maximal payoff for each group of agents in partition $\pi$ be $d\left(P_{j} \mid \pi\right)$, $P_{j} \in \pi$. We implement the following algorithm to calculate $d\left(P_{j} \mid \pi\right), P_{j} \in \pi$.

Algorithm 4.1. We calculate the payoff of $P_{j}, P_{j} \in \pi$ given the disagreement water uses under $\pi$ for those group of agents that can possibly transfer water to any agent within $P_{j}$ is calculated (also including the case that $P_{j}$ has no predecessor) and are common knowledge. Note that the calculation of the payoff of $P_{j}$ can be formulated in a similar way as (7) given all groups' disagreement water uses that can possibly transfer water to any agent within $P_{j}$ are calculated.

We provide one example to illustrate Algorithm 4.1. In this example, we simplify the river geography using the Mekong Basin as represented in Figure 2. The river geography in the Mekong Basin can be expressed as $N=\{$ China, Thailand, Laos, Cambodia, Vietnam $\}$, $P^{\text {China }}=P^{\text {Thailand }}=\emptyset, P^{\text {Laos }}=\{$ China, Thailand $\}, P^{\text {Cambodia }}=\{$ China, Thailand, Laos $\}$ and $P^{\text {Vietnam }}=\{$ China, Thailand, Laos, Cambodia $\}$.

Example 4.2. Four countries in the Mekong River, Laos, Thailand, Cambodia and Vietnam, signed the Mekong Agreement in 1995 and this leaves the most upstream country China alone. The current partition for the Mekong River can be written as $\pi=\left\{P_{1}, P_{2}\right\}$, where $P_{1}=\{$ China $\}$ and $P_{2}=\{$ Laos, Thailand, Cambodia, Vietnam $\}$. Applying Algorithm 4.1, we first calculate $d\left(P_{1} \mid \pi\right)$ because there are no countries that can possibly transfer water to China; then we proceed to $P_{2}$ given that the disagreement point for China is common knowledge.

We need to assign a payoff to each agent $i \in P_{j}, P_{j} \in \pi$.

Definition 4.3. An allocation rule $\gamma$ is a function $v: \Pi \rightarrow \mathbb{R}^{n}$, that assigns a payoff $v_{i}(\pi)$ to any $i \in N$ for all $\pi \in \Pi$.

Group efficiency for allocation rule $\gamma$ is imposed, i.e., we should have $\sum_{i \in P_{j}} v_{i}(\pi)=$ $d\left(P_{j} \mid \pi\right)$ for $P_{j} \in \pi, \pi \in \Pi$. 
The next question is whether the allocation rule $\gamma$ makes partition $\pi$ internally stable. We consider the deviation of one agent leaving their group of agents in partition $\pi$. For some $j$ with $\left|P_{j}\right| \geq 2$, let $i \in P_{j} \subset N$ be the deviating agent that leaves $P_{j} \in \pi$. After agent $i$ leaves $P_{j}$, the new partition will be $\pi^{i}=\left\{P_{1}, P_{2}, \ldots, P_{j} \backslash\{i\},\{i\}, \ldots, P_{m}\right\}$. Note that the new partition is finer and has $m+1$ groups of agents including at least one singleton, namely $\{i\}$. We differentiate the following two cases to calculate $d\left(P_{h} \mid \pi^{i}\right), P_{h} \in$ $\pi^{i}$ after $i$ deviates from $P_{j}$.

1. When $i \in P_{j}$ leaves coalition $P_{j} \in \pi$ and $i$ is in a most upstream position within $P_{j}$ (i.e., $i$ has no predecessors in $P_{j}$ ), it is trivial to see that Algorithm 4.1 still applies to the calculation of $d\left(P_{h} \mid \pi^{i}\right), P_{h} \in \pi^{i}$. In case $i$ is the most downstream agent in $P_{j}$ (i.e., $i$ has no successors in $P_{j}$ ) and the remaining agents in $P_{j}$ are still geographically connected, we can also apply Algorithm 4.1 to calculate the payoff for the remaining agents in $P_{j}$. Note that in case $i$ is positioned most downstream and $i$ 's deviation makes the remaining agents in $P_{j}$ disconnected, e.g., at least two branches in $P_{j}$ merge at $i$, we apply Algorithm 4.1 for subgroups of agents in $P_{j} \backslash\{i\}$ that are connected. Then the payoff for $P_{j} \backslash\{i\}$ is the sum of those subgroups' payoffs.

Example 4.4. In Example 4.2, in case Vietnam (or Thailand) leaves coalition $P_{2}$, then the new partition $\pi^{\text {Vietnam }}$ will be $\{\{$ China $\},\{$ Laos, Thailand, Cambodia $\},\{$ Vietnam $\}\}$. Note that the remaining agents in $P_{2}$ after Vietnam left are still connected to each other. Then we can apply Algorithm 4.1 to calculate the payoff for each coalition in $\pi^{\text {Vietnam }}$.

2. In case that deviating agent $i$ is positioned in between the remaining agents in $P_{j}$, this disconnets the remaining agents in coalition $P_{j} \in \pi$. Then we employ the idea of backward induction from Ambec and Ehlers (2008) to calculate the payoffs $d\left(P_{h} \mid \pi^{i}\right), P_{h} \in \pi^{i}$. Note that there exist an issue whether the upstream agents of the remaining agents in $P_{j} \in \pi$ will pass water to downstream agents of the remaining agents in $P_{j} \in \pi$ because agent $i \in N$ might take some water up to its satiation 
point. In certain cases, the remaining agents in $P_{j}$ still cooperate by passing water from upstream to downstream. In this situation, the cooperation of the remaining agents in $P_{j} \in \pi$ exerts a positive externality on agent $i$ that allows them to reach their satiation point.

Example 4.5. In Example 4.2, suppose that Cambodia deviates from coalition $P_{2}$, then the new partition is $\{\{$ China $\},\{$ Laos, Thailand, Vietnam $\},\{$ Cambodia $\}\}$. There is an issue whether Laos and Thailand will pass water to Vietnam. If so, then Cambodia can reach its satiation point.

As the backward induction procedure discussed in Ambec and Ehlers (2008) mainly focuses on the line river geography, i.e., all agents are positioned on a line, we generalize this procedure to a Y-shaped river geography. In Appendix A, our procedure is explained in detail for such river geography in which two branches merge at a certain location. Let us briefly discuss the main differences here. In the line river geography with only three agents, when the upstream and downstream agents cooperate, they take the midstream agents free riding and its satiation point into account. We initialize the algorithm by sending all water from upstream to downstream, hence rationing the most upstream agents water use to zero. If the shadow price of the rationing constraint is positive, it indicates that the willingness to pay by the upstream agent exceeds the willingness to pay by the downstream agents. Hence, we should ration the upstream agent less in the next iteration and continue to do so until the shadow price of zero is reached. In the Yshaped river geography, there are two upstream agents. In case the two upstream agents cooperate with the most downstream agent, where the agent at the conjunction is the free riding midstream agent, we ration the water use for each upstream agent through their total water use. For line river and Y-shaped river geographies, our algorithm will obtain the optimal water uses and benefits of cooperation in the presence of a free riding midstream agent. Note that we have to compare our solution with the boundary solution that no water is sending down from upstream which might be better than the outcome just described. 
In the following, we introduce the internal stability of a partition, i.e., there exist no profitable unilateral deviation for any $i \in N$.

Definition 4.6. Under allocation rule $\gamma$, partition $\pi$ is internally stable if $v_{i}(\pi) \geq$ $d\left(\{i\} \mid \pi^{i}\right)$ for all $i \in N$.

Proposition 4.7. There exists an allocation rule $\gamma$ to make partition $\pi$ internally stable if and only if $d\left(P_{j} \mid \pi\right) \geq \sum_{i \in P_{j}} d\left(\{i\} \mid \pi^{i}\right)$, for all $P_{j} \in \pi$.

The above proposition is straightforward. Note that it could be well possible that $d\left(P_{j} \mid \pi\right)<\sum_{i \in P_{j}} d\left(\{i\} \mid \pi^{i}\right), P_{j} \in \pi$, see, e.g., Theorem 2 and Example 1 in Ambec and Ehlers (2008). In this scenario, the payoff of the coalition under $\pi$ is not able to satisfy each agent's outside option in terms of unilateral deviation from the current coalition.

Eyckmans and Finus (2004), Weikard (2009) and Weikard et al. (2006) consider only one coalition with more than one agent under $\pi$ and all remaining agents are singleton coalitions. In case there is only one coalition with more than one agent under $\pi$, the definition of internal stability of partition $\pi$ under allocation rule $\gamma$ is equivalent to saying that the only coalition with more than one agent in $\pi$ is internally stable under allocation rule $\gamma$ as argued in the above mentioned literature. In our following application of the Mekong River Basin, there exists only one coalition with more than one agent under the 1995 Mekong Agreement. Therefore, we do not strictly differentiate between the partition of Mekong as mentioned in Example 4.2 is internally stable and that the 1995 Mekong Agreement is internally stable.

\section{Empirical application: the Mekong River Basin}

In this section, we first introduce the background for this empirical study and then the description of our data and our modelling approach. The numerical results for these three scenarios are presented in Section 5.3. Some sensitivity analyses are conducted in Section 5.4. Finally, we discuss some policy implications from the results we have obtained. 


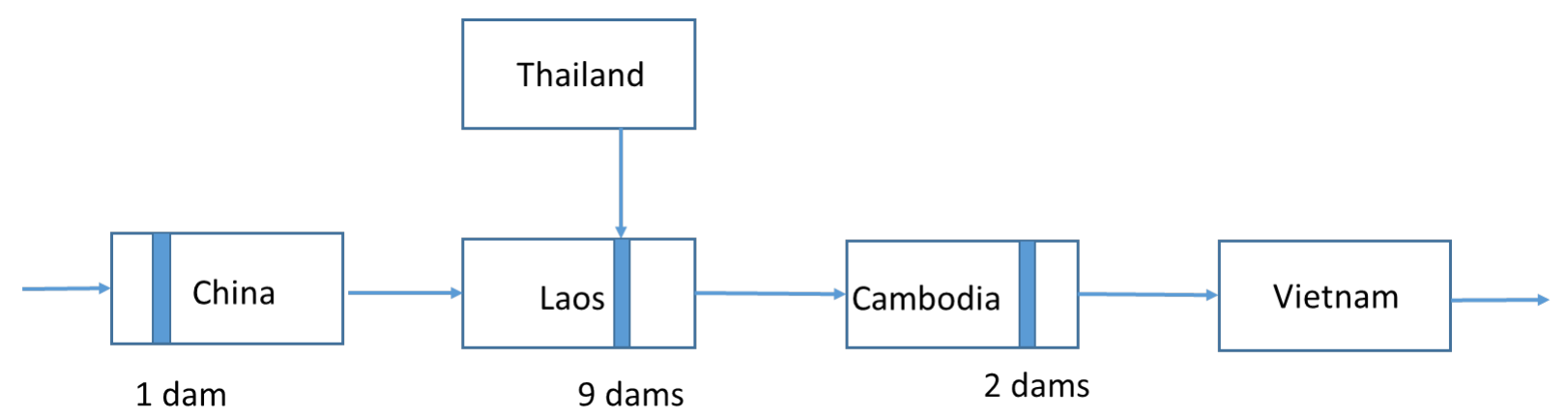

Figure 2: Proposed mainstream dams in the Mekong River Basin Note: Blue bars indicate dams and their location in the Mekong River Basin.

\section{$5.1 \quad$ Background}

The Mekong River runs through China's Yunnan province, Burma, Laos, Thailand, Cambodia and Vietnam, then it flows into the South China Sea. It is not only the source of food and water for more than 70 million people, but the river basin is also home to more than 1,300 species of fish, creating one of the most diverse inland fisheries in the world (Campbell, 2009). In 1995, the four Lower Mekong countries (Laos, Thailand, Cambodia and Vietnam), signed an agreement on the cooperation for the sustainable development of the lower part of the Mekong River Basin. The main spirit of the agreement is for those four countries, being equally desirous, to continue to cooperate in a constructive and mutually beneficial manner for sustainable development, utilization, conservation, and management of the Mekong River Basin. However, the agreement's governance is relatively weak and unstable due to the fact that huge profits of potential hydropower in Laos are pursued without taking into account the negative externalities of dam operation on fishery in Cambodia and salinity in Vietnam. The estimated hydropower potential of the Lower Mekong Basin is 30,000 MW and only 3,235 MW have been met through facilities built largely over the past ten years on the Mekong tributaries (MRC, 2010). Recently, 12 mainstream dams, mainly in Laos, have been proposed, see Figure $2 .{ }^{6}$ All these proposed dams are run-of-the-river hydropower plants and do not have a significant amount of active water storage.

\footnotetext{
${ }^{6}$ These 12 dams are Nuozhadu, Pak Beng, Luang Prabang, Xayaburi, Pak Lay, Sanakham, Pakchom, Ban Koum, Lat Sua, Don Sahong, Stung Treng and Sambor. Except Nuozhadu in China and Stung Treng and Sambor in Cambodia, all other dams are in Laos or on the Laos-Thailand border.
} 
Certain concerns have been raised for the Mekong mainstream hydropower plan, e.g., the fishery in the Lower Mekong Basin will be damaged due to the fact that the fish migration is hindered by those dams (Baron et al., 2007; Ziv et al., 2012; ICEM, 2010). Cambodia, where the main fish reproduction of the Mekong River in the Tonle Sap Lake is located, is likely to bear the brunt of fishery decline as a result of dam development. Furthermore, Ziv et al. (2012) conclude that the closer a dam is located to the Tonle Sap Lake, the larger the negative impact of the dam on the Lower Mekong fishery.

\subsection{Data description and economic modeling}

Hydrological and political considerations determine potential location, type of dams (and its operation), height and capacity. In our analysis, we treat location and height as predetermined by hydrological experts and this leaves us with only the decision to build or not. Let $G_{i_{j}} \in\{0,1\}$ (dam $j$ in agent $i$ 's territory) be a binary variable indicating whether the proposed mainstream dams should be built. In case $G_{i_{j}}=1$, then dam $j$ in the territory of agent $i$ should be built, otherwise it will not. The costs of dam construction are calculated based on the installed capacities. For large hydropower plants, the average investment costs range from as low as USD 1,050 per KW to as high as USD 7,650 per KW (IRENA, 2012). The differences in investment costs in dam construction are mainly due to differences in wages. In this paper, taken the local labor costs in the Mekong River Basin into account, we refer to the cost of dam construction as 5,000 USD per KW. Experience from existing plants worldwide have shown that the life cycle of hydropower dams is in the range of one hundred years or more, but for the economic calculations, a period of 30 years is often used. Therefore, we spread the investment cost over a dam life expectancy of 30 years. The benefits of hydropower dam are calculated based on physical laws and related to the product of hydropower water use and effective dam head. Note that due to the maximum dam installed capacities, we also constrain the hydropower water use in our calculations.

We also take existing tributary dams in Laos and Vietnam (with installed capacity 
of more than $100 \mathrm{MW}$ ) into account. ${ }^{7}$ Note that within a country on the mainstream, the water use for hydropower demonstrates cascade characteristics, i.e., water use for upstream dams in a country can be re-used further for downstream dams. But this is not the case for the hydropower dams on different tributaries. Our model therefore distinguishes between dams on the mainstream and tributaries.

The damage to fishery is calculated according to the distance of the dam to Phnom Penh in Cambodia. The closer the proposed mainstream dam is located to Phnom Penh, the larger the negative impact of this dam on fishery income in Cambodia. ${ }^{8}$ In case dam $i_{j}$ is built, we would expect an impact factor of dam $i_{j}$ to the fishery income $f$ in Cambodia. ${ }^{9}$ According to most recent estimates, Cambodian capture and aquaculture fisheries produce around 527,000 tons of fish, worth between 1.2-1.6 billion USD (FAO, 2011) annually. Fishery production (not including processing and other related activities) thus makes up around 10 percent of Cambodia's overall GDP. The fishery sector also provides full-time, part-time and seasonal employment for up to 6 million people, approximately 40 percent of the population, in capture and subsequent value-adding services (Sothorn et al., 2011). ${ }^{10}$ Thus, a reasonable estimate for the fishery benefit (including direct capture fishery values and indirect employment benefits in the fishery sector) is approximately 4 billion USD. The detailed results of each dam's impact on fishery are reported in Table $1 .^{11}$

The water flow in the Mekong River can be used for other sectors, such as household, industry and irrigation and the water use in the those sectors are consumptive. Note that irrigation takes place only in the dry season in the Mekong River Basin. According to the

\footnotetext{
${ }^{7}$ Among these, we take HouayHo, NamLik2, NamNgum1, NamNgum2, NamTheun2 and TheunHinboun in Laos and Pleikrong, Sesan4, SrePok3 and YaliFalls in Vietnam into account. Details of these dams are included in the Online Appendix.

${ }^{8} \mathrm{Ziv}$ et al. (2012) use the distance from Phnom Penh to measure the fish migration effectiveness. Hence, here we roughly take the dam distance to Phnom Penh to measure the damage on fishery of a certain dam.

${ }^{9}$ In more detail, we assume that in case that all the proposed mainstream dams are built, the fishery income in Cambodia will decline to 0. Impact factors of individual dams are taken to be proportional to its distance to Phnom Penh.

${ }^{10}$ In Cambodia, the average income is about 950 USD per capita per year. So we approximate that 3 million people are fully employed in the fishery sector. Thus, the total amount of value from employment could be 2.85 billion USD.

${ }^{11}$ Note that Nuozhadu is far away from the Tonle Sap Lake, thus we assume that the impact of this dam on the fishery income in Cambodia is 0 .
} 
data in FAO AQUASTAT, irrigation water use constitutes 90 percent of the total water withdrawal in the Mekong River Basin. All details of calculating these benefit functions for household, industry, hydropower and irrigation sectors are presented separately in the Online Appendix.

In this empirical part of the study, a large amount of results are focused on the externalities of dam constructions in Laos on fishery income in Cambodia. In the disagreement scenario, the Laos government builds dams without taking the externalities on fishery in Cambodia into account. Therefore, when we calculate the disagreement scenario for Cambodia, it has to bear the externalities of fishery decline from dam construction of Laos. Cambodia can only internalize the externalities on fishery from its own dam constructions. In the scenario of joint cooperation and partial cooperation with respect to (7), the externalities between Laos and Cambodia will be internalized only when Laos and Cambodia are included in the same coalition.

In a nutshell, we formulate the empirical maximization problem (1)-(4) for the Mekong River Basin in the following way:

$$
\begin{aligned}
& \max _{x_{i, k, s}, q_{i, s}, G_{i_{1}}, \cdots, G_{i_{i}}} \sum_{k \in K} \sum_{s \in S} b_{i, k}\left(x_{i, k, s}\right)+\sum_{s \in S} Q_{i}\left(q_{i, s}, \sum_{j=1}^{n_{i}} G_{i_{j}}\right)-\sum_{j=1}^{n_{i}} c G_{i_{j}} D_{i_{j}}-i n d_{i} \cdot f \sum_{j=1}^{n_{i}} G_{i_{j}} i m f_{i_{j}} \\
& \text { s.t. } \quad \sum_{k \in K} x_{i, k, w}+q_{i, w}+r_{i} \leq e_{i, w}+o_{i, w} \\
& \quad \sum_{k \in K} x_{i, k, d}+q_{i, d} \leq e_{i, d}+o_{i, d}+r_{i},
\end{aligned}
$$

where $o_{i, w}$ and $o_{i, d}$ are as in (5) and (6), $G_{i_{j}}, j=1, \cdots, n$ indicates whether mainstream dam $j$ will be built on agent $i$ 's territory, $c$ is the cost in USD per KW, $D_{i_{j}}$ is the proposed installed capacity of dam $i_{j}$ and $i m f_{i_{j}}$ is the impact factor of dam $i_{j}$ on fishery income in Cambodia. ${ }^{12}$ Note that $i n d_{i}$ is an indicator. For the calculation of the disagreement scenario of Cambodia, ind $_{i}$ is taken to be 1. For other countries' disagreement calculation, ind $_{i}$ is taken to be 0 . Note that the cumulative impact of dam construction from agent

\footnotetext{
${ }^{12}$ With a slight abuse of notation, here $D_{i_{j}}$ refers to the installed capacities of hydropower dams instead of the reservoir dam capacities introduced in Section 2.
} 
$i$ on the fishery income in Cambodia is the sum of the impact of individual proposed mainstream dams as expressed by $\sum_{j=1}^{n_{i}} G_{i_{j}} i m f_{i_{j}}$.

In the following, we are interested in the disagreement and joint cooperation scenarios. In addition, we are interested in the total payoffs for the four countries under the 1995 Mekong Agreement and also in the scenario of unilateral deviation within the 1995 Mekong Agreement. In summary, the following seven coalitional structures are interesting for us:

1. $\{$ China $\},\{$ Thailand $\},\{$ Laos $\},\{$ Cambodia $\},\{$ Vietnam $\}$ : the disagreement scenario;

2. $\{$ China $\},\{$ Thailand $\},\{$ Laos, Cambodia, Vietnam $\}$ : Thailand deviates from the 1995 Mekong Agreement;

3. $\{$ China $\},\{$ Vietnam $\},\{$ Thailand, Laos, Cambodia $\}$ : Vietnam leaves the 1995 Mekong Agreement;

4. $\{$ China $\}$, \{Thailand, Laos, Cambodia, Vietnam\}: the 1995 Mekong Agreement;

5. $\{$ China $\},\{$ Laos $\},\{$ Thailand, Cambodia, Vietnam $\}$ : Laos deviates from the 1995 Mekong Agreement;

6. $\{$ China $\}$, $\{$ Cambodia\}, \{Thailand, Laos, Vietnam\}: Cambodia leaves the 1995 Mekong Agreement;

7. $\{$ China, Thailand, Laos, Cambodia, Vietnam\}: the joint cooperation scenario.

Note that each scenario refers to a coalition structure. We calculate these seven scenarios in GAMS. ${ }^{13}$ Here we illustrate the main idea of the calculation. Firstly, note that there are substantial differences in calculating the values between coalitions that are connected and coalitions that are not, as discussed in Section $4 .{ }^{14}$ For the latter scenario (i.e., scenarios 5 and 6), we apply the algorithm of backward induction proposed by Ambec and Ehlers (2008). For all geographically connected coalitions, we apply Algorithm 4.1. The main idea is that a coalition (or a country) is able to calculate its payoff conditional

\footnotetext{
${ }^{13}$ Our GAMS code is available upon request.

${ }^{14}$ By saying that the coalitions are not geographically connected, we refer to the case in Example 4.5.
} 
on all its predecessors' payoff and water consumptive uses are calculated and are common knowledge. We first calculate scenario 1, i.e., the disagreement scenario. Given that China and Thailand's disagreement points are calculated, we proceed to scenario 2. Given that China's disagreement point is calculated, we proceed to scenario 3 , then to scenario 4 . Since the coalitions in scenarios 5 and 6 are not connected, we will apply the algorithm of backward induction in Ambec and Ehlers (2008) to calculate the payoffs in these scenarios. Finally, we end up the calculation with the grand coalition in scenario 7.

\section{$5.3 \quad$ Numerical results}

In Table 1, we report the relevant parameters of the proposed mainstream dam and whether these dams should be built under different scenarios. In Table 2, we report the economic value for all coalitions in different coalition structures. In Table 3, we report the economic value of hydropower from mainstream dams in Laos and fishery income in Cambodia for different coalition structures.

The water use amount for household, industry and irrigation is very close to the satiation point of water use in all seven scenarios. This leads to the conclusion that water scarcity is less problemetic in the Mekong River Basin. Similar results can be found in Ringler et al. (2004), "competition for Mekong water still appears to be low". In Appendix C, we report the water use amount of each sector in the disagreement scenario. The water use amounts in other scenarios are quite similar.

In the following, we report the results for each scenario separately. The main focus of our results are on the total economic value and the trans-boundary externalities of dam constructions in Laos on the fishery in Cambodia. Indeed, in case that Cambodia and Laos are included in the same coalition, the trans-boundary externality issues of dam construction on fishery are internalized and this results in a higher payoff for the fishery sector in Cambodia and relatively lower benefits from hydropower in Laos (Table 3). 


\subsubsection{The disagreement scenario}

We adapt the ATS principle and calculate the disagreement point for each country in the Mekong River Basin. There are externalities of dam construction in Laos on fishery income in Cambodia. Without taking Cambodia's benefits into account, Laos builds dams for its own benefit. In case all proposed mainstream dams in Laos are built, fishery income in Cambodia will decrease to 57.2 percent of the current income (Table 1). With the potential of hydropower benefits in our model, the total benefits of the water economy in Laos will boom at a level of 15.400 billion USD (Table 2). ${ }^{15}$ According to our calculations, Mekong mainstream dams will boom Laos's benefits by an amount of 10.936 billion USD (Table 3). ${ }^{16}$ With mainstream dam construction, fishery in Cambodia will be significantly damaged. Note that in this scenario, all proposed mainstream dams in Laos will be built (Table 1).

\subsubsection{The joint cooperation scenario}

In case that all countries in the Mekong River Basin cooperate, they internalize the externalities of dam construction in Laos on fishery income in Cambodia. Then, some proposed dams in Laos, i.e., Xayaburi, Pak Lay, Bankoum, Lat Sua and Don Sahong, will not be built in this scenario (Table 1). The total economic value of the grand coalition is calculated to be around 45.653 billion USD for the whole river basin (Table 2). This leads to a welfare increase of 1.302 billion USD for the whole river basin compared with the disagreement scenario.

\subsubsection{The partial cooperation scenario}

Finally, we consider the scenario of strong governance of the 1995 Agreement that all countries in the Lower Mekong River Basin would pursue the goal of a sustainable longterm development and a maximal total economic benefit. Part of the goal involves how to

\footnotetext{
${ }^{15}$ The gross domestic product (GDP) for Laos in 2013 is reported around 11.24 billion USD (World Bank, 2015).

${ }^{16}$ According to our calculations, the yearly hydropower production at the Xayaburi dam will be roughly 2903.7 GWh in the disagreement scenario which is a quite reasonable estimate to the primary energy production of 4231.8 GWh reported in Poyry (2011).
} 
distribute the benefits to sustain cooperation. We employ the idea of "internal stability", i.e., the total benefits of the coalition should be able to satisfy each country's outside option, and the outside option is defined as each country's payoff in case of their unilateral deviation. In case that Thailand or Vietnam deviates from the 1995 Agreement, the remaining three countries in the agreement are still geographically connected. In case that Laos or Cambodia deviates, the remaining 1995 agreement is not geographically connected and we apply the algorithm developed in Appendix A.

According to our calculations, the total economic value for the Lower Mekong Basin is around 36.553 billion USD (Table 2). The outside option of each country in the 1995 Mekong Agreement is also reported in Table 2. The sum of these outside options (35.251 billion USD) is lower than the total economic benefits of the 1995 Mekong Agreement. Therefore, the 1995 Mekong Agreement is internally stable in terms of unilateral deviations. The rationale is as follows: the scarcity of water use is less problemetic but instead the trans-boundary externalities of dam projects on fishery sector is more prominent in the Lower Mekong River Basin. In case that Laos or Cambodia deviates from the 1995 Mekong Agreement, these externalities are not internalized.

\subsection{Sensitivity analysis}

We conduct some sensitivity analyses in this section. As mentioned in Section 5.2, the differences in dam construction costs are mainly due to differences in wages. We might lower the dam construction costs from 5,000 USD per KW to 4,000 USD per KW given the lower labor costs in the Mekong River Basin. All results for dam construction reported in Table 1 remain the same. As the dam construction decreases, we expect a higher hydropower benefit for Laos as reported in Table 5 (in Appendix B). Also, the 1995 Mekong Agreement remains internally stable in terms of unilateral deviations as the results in Table 4 (in Appendix B) demonstrate. 


\subsection{Some economic interpretations and policy discussions}

In almost all cases, an agreement involving all relevant riparian countries will deliver the maximum amount of basin-wide benefits. However, as mentioned in the introduction, China is not included in the 1995 Mekong Agreement. One common view is that the Lower Mekong countries might lose their bargaining power in the agreement (i.e., a small $\alpha_{i}$ vis-à-vis China in Proposition 3.1 for Lower Mekong countries) because of the super political power of China leading China to reap all the economic benefits of the agreement. Our findings in this paper provide an explanation from another perspective: the marginal economic contribution for China to join the 1995 Mekong Agreement (almost zero) is not considered significant from the standpoint of the Lower Mekong countries as our empirical results in Table 2 demonstrate. Similar empirical evidence can be found in Houba et al. (2013).

As discussed in Dinar et al. (2013: 280), "It should be noted that despite persistent efforts at cooperation on management of the Mekong's shared-water resources, the Basin regime has thus far produced little tangible evidence of such cooperation." Similarly, the weak governance of the 1995 Mekong Agreement is also manifested in Houba et al. (2013), "the current situation represents 'weak' governance in which the different water users maximize their own profits without taking into account the externalities they cause and where the interests of dam operators are given priority". Other factors, such as the impact of climate change on water flow in the basin and the unilateral hydropower development plan in China will also change the flow regime in the entire river basin and might negatively affect the ability to manage the Mekong River basin cooperatively. If the Mekong River Commission cannot improve its governance, we might eventually end up with the most inefficient scenario, i.e., the disagreement scenario, taking all the above mentioned factors into account.

Thailand and Vietnam have the largest energy demand among the Lower Mekong countries and in total account for 96 percent of energy demand in the Lower Mekong basin by 2025 (ICEM, 2010). The energy demand for Thailand is estimated with an average annual increase of 2,600 MW per year between 2010 and 2025, whereas the annual increase 
in peak demand for Vietnam is estimated to be roughly 4,600 MW per year between 2010 and 2025 (ICEM, 2010). Laos is the greatest beneficiary of the economic benefits directly associated with mainstream hydropower to meet the increasing energy demand in Thailand and Vietnam and the electricity export revenues for Laos are estimated to be around 2.6 billion USD (ICEM, 2010). In this perspective, Thailand, Laos and Vietnam might form a sub-coalition driven by electricity supply and demand, while neglecting the negative externalities of the dam construction on fishery in Cambodia.

\section{Concluding remarks}

In this paper, we extend the current literature on water resource allocations in transboundary river basins by adding the possibility of building dams and conducting a thorough analysis of costs and benefits of dam construction. Three scenarios arising from exogenous institutional factors are analyzed, i.e., the disagreement scenario in which each agent pursues their own interests, the joint cooperation scenario across the whole river basin to extract maximal benefits, and partial cooperation scenario between neighboring river basin agents. One key issue is the presence of trans-boundary externalities, i.e., dam construction in upstream countries on downstream countries. We examine our approach further in detail in the Mekong River Basin. Indeed, the negative externalities of dam construction in Laos on fishery income in Cambodia are internalized if both Laos and Cambodia are included in the same coalition. This requires that Laos does not build all of the planned mainstream dams. We also conclude that the 1995 Mekong Agreement among the Lower Mekong countries is internally stable in terms of unilateral deviations.

Our paper demonstrates in one model a combination of a solid engineering background with economic considerations and strategic behavior of (state) decision makers at the basin level. It is based on a very realistic set of scenarios, taken from planning reports of the dams in the various Mekong Basin States. It is comprehensive in nature in the sense that it addresses a multi sector (agriculture, electricity, fishery, environment and urban), which none of the models applied before have shown. It uses best available up-to-date 
datasets in the empirical calculations. In that regards, the paper developed a generic model which can be extrapolated also to other basins around the world in a relatively fast and easy way.

Further empirical research could extend the analysis to include more relevant externalities, e.g., the environmental and/or ecological costs. For instance, due to the dam construction, the local environment might be impacted and people have to be relocated. It is necessary that more relevant data become available to assess relevant benefits and costs more accurately. In addition, the water flow amount in the basin is taken to be average flow amount based on historical data in this paper. Hence, the results obtained in this paper might be vulnerable to some extreme events, for instance, droughts or floods, see e.g., Blankspoor et al. (2014). However, our model can be easily extended to include these events as well. 
Table 1: Relevant parameters of the proposed Mekong mainstream dams and whether these dams should be built in different coalition structures

\begin{tabular}{|c|c|c|c|c|c|c|c|c|c|c|c|c|}
\hline Name of the proposed dam & Nuozhadu & Pak Beng & Luang Prabang & Xayaburi & Pak Lay & Sanakham & Pakchom & Ban Koum & Lat Sua & Don Sahong & Stung Treng & Sambor \\
\hline Dams in which country & China & Laos & Laos & Laos & Laos & Laos & Laos & Laos & Laos & Laos & Cambodia & Cambodia \\
\hline Installed capacity of the proposed dam (MW) & 5,850 & 1,230 & 1,410 & 1,285 & 1,320 & 700 & 1,079 & 1,872 & 686 & 240 & 980 & 2,600 \\
\hline Distance to Phnom Penh, Cambodia (KM) & $\mathrm{N} / \mathrm{A}$ & 2389.6 & 2247.8 & 2035.1 & 1928.7 & 1857.8 & 1690.5 & 850.9 & 680.7 & 510.5 & 404.2 & 312 \\
\hline Impact on the fishery income in Cambodia (\%) & 0 & 0.031 & 0.033 & 0.037 & 0.039 & 0.041 & 0.045 & 0.088 & 0.111 & 0.147 & 0.186 & 0.241 \\
\hline$\{$ China $\},\{$ Thailand $\},\{$ Laos $\},\{$ Cambodia $\},\{$ Vietnam $\}$ & 0 & 1 & 1 & 1 & 1 & 1 & 1 & 1 & 1 & 1 & 0 & 1 \\
\hline$\{$ China $\},\{$ Thailand $\},\{$ Laos, Cambodia, Vietnam $\}$ & 0 & 1 & 1 & 0 & 0 & 1 & 1 & 0 & 0 & 0 & 0 & 1 \\
\hline$\{$ China $\},\{$ Vietnam $\},\{$ Thailand, Laos, Cambodia $\}$ & 0 & 1 & 1 & 0 & 0 & 1 & 1 & 0 & 0 & 0 & 0 & 1 \\
\hline$\{$ China $\},\{$ Thailand, Laos, Cambodia, Vietnam $\}$ & 0 & 1 & 1 & 0 & 0 & 1 & 1 & 0 & 0 & 0 & 0 & 1 \\
\hline$\{$ China $\},\{$ Laos $\},\{$ Thailand, Cambodia, Vietnam $\}$ & 0 & 1 & 1 & 1 & 1 & 1 & 1 & 1 & 1 & 1 & 0 & 1 \\
\hline$\{$ China $\},\{$ Cambodia $\},\{$ Thailand, Laos, Vietnam $\}$ & 0 & 1 & 1 & 1 & 1 & 1 & 1 & 1 & 1 & 1 & 0 & 1 \\
\hline$\{$ China, Thailand, Laos, Cambodia, Vietnam\} & 0 & 1 & 1 & 0 & 0 & 1 & 1 & 0 & 0 & 0 & 0 & 1 \\
\hline
\end{tabular}

Data of the installed capacity is taken from ICEM (2009). Note "1" ("0") indicates that the dam should (not) be built. 
Table 2: Payoffs for each coalition in different coalition structures in billion USD

\begin{tabular}{|c|c|c|c|c|c|}
\hline The coalition structures & China & Thailand & Laos & Cambodia & Vietnam \\
\hline$\{$ China $\},\{$ Thailand $\},\{$ Laos $\},\{$ Cambodia $\},\{$ Vietnam $\}$ & 9.100 & 8.373 & 15.400 & 4.203 & 7.275 \\
\hline$\{$ China $\},\{$ Thailand $\},\{$ Laos, Cambodia, Vietnam $\}$ & 9.100 & 8.373 & \multicolumn{3}{|c|}{28.180} \\
\hline$\{$ China $\},\{$ Vietnam $\},\{$ Thailand, Laos, Cambodia $\}$ & 9.100 & \multicolumn{3}{|c|}{29.278} & 7.275 \\
\hline$\{$ China $\},\{$ Thailand, Laos, Cambodia, Vietnam $\}$ & 9.100 & \multicolumn{4}{|c|}{36.553} \\
\hline$\{$ China $\},\{$ Laos $\},\{$ Thailand, Cambodia, Vietnam $\}$ & 9.100 & $\mathrm{~A}$ & 15.400 & \multicolumn{2}{|c|}{$\mathrm{A}$} \\
\hline$\{$ China $\},\{$ Cambodia $\},\{$ Thailand, Laos, Vietnam $\}$ & 9.100 & \multicolumn{2}{|c|}{$\mathrm{B}$} & 4.203 & $\mathrm{~B}$ \\
\hline$\{$ China, Thailand, Laos, Cambodia, Vietnam $\}$ & \multicolumn{5}{|c|}{45.653} \\
\hline
\end{tabular}

Note that $A$ denotes the coalition value of Thailand, Cambodia and Vietnam and is equal to 19.852 , and $B$ denotes the coalition value of Thailand, Laos and Vietnam and is equal to 31.048.

Table 3: Fishery income in Cambodia and hydropower benefits for mainstream Laos in different coalition structures in billion USD

\begin{tabular}{|c|c|c|}
\hline The coalition structures & Hydropower Laos & Fishery Cambodia \\
\hline$\{$ China $,\{$ Thailand $\},\{$ Laos $\},\{$ Cambodia $\},\{$ Vietnam $\}$ & 10.936 & 0.748 \\
\hline$\{$ China $,\{$ Thailand $\},\{$ Laos, Cambodia,, Vietnam $\}$ & 10.550 & 2.436 \\
\hline$\{$ China $,\{$ Vietnam $\},\{$ Thailand, Laos, Cambodia $\}$ & 10.550 & 2.436 \\
\hline$\{$ China,$\{$ Thailand, Laos, Cambodia, Vietnam $\}$ & 10.550 & 2.436 \\
\hline$\{$ China $,\{$ Laos $\},\{$ Thailand, Cambodia, Vietnam $\}$ & 10.936 & 0.748 \\
\hline$\{$ China,$\{$ Cambodia,$\{$ Thailand, Laos, Vietnam $\}$ & 10.936 & 0.748 \\
\hline$\{$ China, Thailand, Laos, Cambodia, Vietnam $\}$ & 10.550 & 2.436 \\
\hline
\end{tabular}




\section{A Algorithm of backward induction}

In this Appendix, we provide a robust numerical implementation of the algorithm proposed in Ambec and Ehlers (2008) and extend it to general river geographies and seasonal models.

If agent $i$ leaves the connected coalition $P_{j}$, then $P_{j} \backslash\{i\}$ either remains connected or it falls apart in at least two connected subcoalitions. The case $P_{j} \backslash\{i\}$ remains connected (because $i$ is either most upstream or most downstream in $P_{j}$ but not being at a confluence of tributaries) is already described in the main text. The generic case of $P_{j}$ falling apart into several connected subcoalitions that captures all relevant possibilities can be described by a river graph with four connected subcoalitions, called agents, numbered $U_{1}$, $U_{2}, i$ and $D$. All four together represent $P_{j}$, where agent $U_{1}$ and agent $U_{2}$ represent the remaining connected subcoalitions on one of two tributaries that join at agent $i$ before the river flows to the remaining connected downstream subcoalition represented by agent $D$. For ease of notation, we treat connected subcoalitions as single agents and write $x_{U_{1}}$, $b_{U_{1}}\left(x_{U_{1}}\right)$ and $e_{U_{1}}$, etc. as if these are scalars.

The shape of the graph representing these four agents can be represented by a $Y$ shaped river geography, where $i$ connects all three endpoints. The $Y$-shaped captures all relevant cases, as can be seen as follows. A line river where $i$ separates $U_{1}$ and $D$ is obtained as a special case in which either $U_{2}$ is the empty subcoalition or $U_{2}$ has no resources, i.e., $e_{U_{2}}=0$. The special case of a $V$-shaped river geography in which $i$ is most downstream and connects two tributaries, $U_{1}$ and $U_{2}$, can be captured by assuming either the empty subcoalition $D$, or the absence of any benefits at $D$, i.e., $b_{D}\left(x_{D}\right)=0$ for all $x_{D} \geq 0$. In case of more than two tributaries that merge at $i$, we might add members of $P_{j} \backslash\{i\}$ along these tributaries as agents $U_{3}, U_{4}$ etc. So, two tributaries representing two upstream connected subcoalitions of $P_{j} \backslash\{i\}$ and one connected downstream subcoalition of $P_{j} \backslash\{i\}$ describes the generic case and exhausts all relevant special cases.

For explanatory reasons, we describe the algorithm for an annual model in detail. The key idea of the algorithm is that the joint water use of $U_{1}$ and $U_{2}$ is drastically rationed, initially even to zero, sending large amounts of water downstream. Each iteration consists 
of solving two convex programs. First, to determine the amount agent $i$ takes up to his satiation point $\bar{x}_{i}$, and second, a nonlinear program that determines the shadow price on the constraint describing the rationing of $U_{1}$ and $U_{2}$. Formally, we add the constraint $x_{U_{1}}+x_{U_{2}} \leq x_{r}$, where $x_{r}$ denotes the total amount of rationing imposed upon both upstream agents. The algorithm deals with updating $x_{r}$ between iterations. Agent $i$ receives inflow $e_{U_{1}}+e_{U_{2}}-x_{r}$ from upstream. For given $x_{r}$, agent $i$ solves the convex program

$$
\bar{x}_{i}=\arg \max _{x_{i} \geq 0} b_{i}\left(x_{i}\right) \text {, s.t. } x_{i}+x_{r} \leq e_{U_{1}}+e_{U_{2}}+e_{i},
$$

where $\bar{x}_{i}$ can be regarded as the reaction function $\bar{x}_{i}\left(x_{r}\right)$ of how $i$ responds to $x_{r}$. Given this reaction $\bar{x}_{i}$, we solve the convex program for the disconnected coalition $P_{j} \backslash\{i\}$ taking the rationing explicitly into account

$$
\begin{array}{rlr}
\max _{x_{U_{1}}, x_{U_{2}}, x_{D} \geq 0} b_{U_{1}}\left(x_{U_{1}}\right)+b_{U_{2}}\left(x_{U_{2}}\right)+b_{D}\left(x_{D}\right), & \\
\text { s.t. } \quad x_{U_{1}} & \leq e_{U_{1}}, & \left(\lambda_{U_{1}}\right) \\
x_{U_{2}} & \leq e_{U_{2}}, & \left(\lambda_{U_{2}}\right) \\
x_{U_{1}}+x_{U_{2}}+\bar{x}_{i}+x_{D} & \leq e_{U_{1}}+e_{U_{2}}+e_{i}+e_{D}, & \left(\lambda_{D}\right) \\
x_{U_{1}}+x_{U_{2}} & \leq x_{r}, & (\mu)
\end{array}
$$

where denote $\lambda_{U_{1}}, \lambda_{U_{2}}, \lambda_{D}$ and $\mu$ shadow prices. These shadow prices are non-negative because the program is a convex program. From the corresponding first-order conditions, we report only

$$
\begin{aligned}
b_{U_{1}}^{\prime}\left(x_{U_{1}}\right)-\lambda_{U_{1}}-\lambda_{D}-\mu & =0, \\
b_{U_{2}}^{\prime}\left(x_{U_{2}}\right)-\lambda_{U_{2}}-\lambda_{D}-\mu & =0, \\
b_{D}^{\prime}\left(x_{D}\right)-\lambda_{D} & =0 .
\end{aligned}
$$


From the first-order conditions, we obtain $\lambda_{D}=b_{D}^{\prime}\left(x_{D}\right)$ and

$$
\mu=b_{U_{1}}^{\prime}\left(x_{U_{1}}\right)-b_{D}^{\prime}\left(x_{D}\right)-\lambda_{U_{1}}=b_{U_{2}}^{\prime}\left(x_{U_{2}}\right)-b_{D}^{\prime}\left(x_{D}\right)-\lambda_{U_{2}} .
$$

We will continue by describing the algorithm in detail. The consecutive execution of the above two convex programs describe a single iteration of the algorithm. The algorithm is initialized at $x_{r}=0$ and it adjusts $x_{r}$ based on the shadow price $\mu$. For arbitrary $x_{r} \in\left[0, e_{U_{1}}+e_{U_{2}}\right]$, we distinguish the following four cases at the end of each iteration:

Case $1 x_{U_{1}}<e_{U_{1}}$ and $x_{U_{2}}<e_{U_{2}}$. Then, $x_{r}<e_{U_{1}}+e_{U_{2}}, \lambda_{U_{1}}=\lambda_{U_{2}}=0$ and through $\mu$ the program equates the marginal benefits $b_{U_{1}}^{\prime}\left(x_{U_{1}}\right)=b_{U_{2}}^{\prime}\left(x_{U_{2}}\right)$. Note that all marginal benefits can be reinterpreted as willingness to pay for water by the agent involved. So, $\mu>0$ indicates that the willingness to pay by both upstream agents exceeds the willingness to pay by the downstream agent. Welfare within the disconnected coalition $U_{1}, U_{2}$ and $D$ can be increased by rationing upstream less. If $\mu=0$, we should not relax the rationing. At the end of each iteration, the algorithm will slightly relax the rationing $x_{r}$ if $\mu>0$ and the iterations stop if $\mu=0$. Note that $x_{r}<e_{U_{1}}+e_{U_{2}}$ indicates that a slight relaxation of rationing $x_{r}$ is feasible. With two tributaries merging at $i$, the initialization $x_{r}=0$ belongs to Case 1 . The special case of $P_{j}$ being described by unsatiated upstream demand for water and a $V$-shaped river geography, i.e., $d_{D}\left(x_{D}\right)=0$, necessarily has $\mu>0$ for all $x_{r}<e_{U_{1}}+e_{U_{2}}$ and also belongs to Case 1 .

Case $2 x_{U_{1}}<e_{U_{1}}$ and $x_{U_{2}}=e_{U_{2}}$. Then, $x_{r}<e_{U_{1}}+e_{U_{2}}, \lambda_{U_{1}}=0, \mu=b_{U_{1}}^{\prime}\left(x_{U_{1}}\right)-$ $b_{D}^{\prime}\left(x_{D}\right) \geq 0$ and $\lambda_{U_{2}}=b_{U_{1}}^{\prime}\left(x_{U_{1}}\right)-b_{U_{2}}^{\prime}\left(x_{U_{2}}\right) \geq 0$. The shadow prices $\mu \geq 0$ indicates that $U_{1}$ has a larger willingness to pay than $D$, and $\lambda_{U_{2}}$ indicates the welfare improving consequences of the infeasible trade of water from $U_{2}$ to $U_{1}$. As before, $\mu>0$ indicates that welfare within the disconnected coalition $U_{1}, U_{2}$ and $D$ can be increased by relaxing rationing $x_{r}$. If $\mu=0$, we should not relax and stop the iterations. At the end of each iteration, the algorithm will slightly relax 
the rationing $x_{r}$ if $\mu>0$ and it stops if $\mu=0$. The special case of a line river, i.e., $e_{U_{2}}=0$, always belongs to Case 2. As before, $x_{r}<e_{U_{1}}+e_{U_{2}}$ allows a slight relaxation of rationing.

Case $3 x_{U_{1}}=e_{U_{1}}$ and $x_{U_{2}}<e_{U_{2}}$ is similar to Case 2 .

Case $4 x_{U_{1}}=e_{U_{1}}$ and $x_{U_{2}}=e_{U_{2}}$. This case is a a boundary solution and can only occur if $x_{r}=e_{U_{1}}+e_{U_{2}}$ also holds. Having initialized the algorithm at $x_{r}=0$ and after having increased $x_{r}$, we have reached a boundary solution. Then, $\mu>0$ indicates that upstream's willingness to pay exceeds downstream's willingness to pay and this boundary solution is optimal. The special case of $P_{j}$ being described by unsatiated upstream demand for water and a $V$-shaped river geography, i.e., $d_{D}\left(x_{D}\right)=0$, will continue to relax $x_{r}$ until Case 4 will be reached.

Expressed in terms of infinitesimal relaxations of $x_{r}$, we have the differential equation $\dot{x}_{r}=\mu\left(x_{r}\right)$ governing the evolution of $x_{r}$ and $\dot{x}_{r}=0$ whenever $\mu\left(x_{r}\right)=0$. So, initializing at $x_{r}=0$, once $\mu\left(x_{r}\right)=0$ is reached the logic of the programs dictates that it will reach $\mu\left(x_{r}\right)$ at the smallest $x_{r}^{*}<e_{U_{1}}+e_{U_{2}}$ and that $\mu\left(x_{r}\right)$ remains 0 for all $x_{r}>x_{r}^{*}$. The key idea of the algorithm is to iterate the above two programs until either the smallest $x_{r}^{*}$ is reached on the range of $x_{r}$ for which $\mu\left(x_{r}\right)=0$ or the ceiling $x_{r}=e_{U_{1}}+e_{U_{2}}$ is reached. Because of $\mu\left(x_{r}\right)=0$ for relatively large values of $x_{r}$ it is necessary to start the algorithm at $x_{r}=0$. Also, because $x_{r}^{*}$ on the interior of $\left[0, e_{U_{1}}+e_{U_{2}}\right]$ induces free riding by agent $i$, we need to compare its associated solution with the boundary solution $x_{U_{1}}=e_{U_{1}}$, $x_{U_{2}}=e_{U_{2}}$ and $x_{D}=e_{D}$ that excludes any such free riding, where the latter boundary can also be seen as inaction. This comparison will be conducted after the iterations stop. In implementing the algorithm,we increase $x_{r}$ by a small but positive stepsize that is proportional to $\mu\left(x_{r}\right)$ and this may cause small numerical inaccuracies in computing $x_{r}^{*}$.

Next, we will show that this algorithm stops in the optimal water allocation among the members of $P_{j} \backslash\{i\}$. The algorithm is initialized at $x_{r}=0$.

If $\mu=0$ in the first iteration, it stops at the boundary solution $x_{U_{1}}=x_{U_{2}}=0$ and $x_{D}=e_{U_{1}}+e_{U_{2}}+e_{i}+e_{D}-\bar{x}_{i}>0$. In this case, $\mu\left(x_{r}\right)=0$ for all $x_{r} \in\left[0, e_{U_{1}}+e_{U_{2}}\right]$. Then, 
we need to compare this boundary solution with the other boundary solution $x_{U_{1}}=e_{U_{1}}$, $x_{U_{2}}=e_{U_{2}}$ and $x_{D}=e_{D}$.

If $\mu>0$ in the first iteration, rationing $x_{r}$ will be relaxed in consecutive iterations until either the smallest $x_{r}^{*} \in\left(0, e_{U_{1}}+e_{U_{2}}\right)$ is reached where $\mu$ either equals 0 or $x_{r}$ hits its ceiling associated with the boundary solution $x_{U_{1}}=e_{U_{1}}, x_{U_{2}}=e_{U_{2}}$ and $x_{D}=e_{D}$. In the first case, $x_{r}^{*}$ is the optimal rationing on the interior of $\left[0, e_{U_{1}}+e_{U_{2}}\right]$ and $\mu\left(x_{r}\right)=0$ for all $x_{r} \geq x_{r}^{*}$. Then, we need to compare the solution associated with $x_{r}^{*}$ with the other boundary solution $x_{U_{1}}=e_{U_{1}}, x_{U_{2}}=e_{U_{2}}$ and $x_{D}=e_{D}$. In the second case, $\mu\left(x_{r}\right)>0$ for all $x_{r}<e_{U_{1}}+e_{U_{2}}$ must hold and the algorithm continuous iterating until $x_{r}=e_{U_{1}}+e_{U_{2}}$ will be reached. Then, the boundary $x_{U_{1}}=e_{U_{1}}, x_{U_{2}}=e_{U_{2}}$ and $x_{D}=e_{D}$ is clearly optimal.

To summarize, the above arguments show that our algorithm is guaranteed to converge and that we obtain disconnected coalition $P_{j} \backslash\{i\}$ 's correct value from cooperation that takes into account optimal free riding by agent $i$.

For the application of the seasonal model to the Mekong basin, we implemented the above algorithm after modifying it for rationing each upstream's water use per season. Shadow prices of these rationing equations were used to control relaxing the rationed amounts proportional to their shadow prices.

\section{B Sensitivity analysis}

In Table 4 and 5, we report the results with the dam constrution costs are taken to be 4,000 USD per KW instead of 5,000 USD per KW. 
Table 4: Payoffs for each coalition in different coalition structures in billion USD $(c=4,000)$

\begin{tabular}{|c|c|c|c|c|c|}
\hline The coalition structures & China & Thailand & Laos & Cambodia & Vietnam \\
\hline$\{$ China $\},\{$ Thailand $\},\{$ Laos $\},\{$ Cambodia $\},\{$ Vietnam $\}$ & 9.100 & 8.373 & 15.727 & 4.290 & 7.275 \\
\hline$\{$ China $\},\{$ Thailand $\},\{$ Laos, Cambodia, Vietnam $\}$ & 9.100 & 8.373 & \multicolumn{3}{|c|}{28.414} \\
\hline$\{$ China $\},\{$ Vietnam $\},\{$ Thailand, Laos, Cambodia $\}$ & 9.100 & \multicolumn{3}{|c|}{29.512} & 7.275 \\
\hline$\{$ China $\},\{$ Thailand, Laos, Cambodia, Vietnam $\}$ & 9.100 & \multicolumn{4}{|c|}{36.787} \\
\hline$\{$ China $\},\{$ Laos $\},\{$ Thailand, Cambodia, Vietnam $\}$ & 9.100 & $\mathrm{~A}$ & 15.727 & \multicolumn{2}{|c|}{$\mathrm{A}$} \\
\hline$\{$ China $\},\{$ Cambodia $\},\{$ Thailand, Laos, Vietnam $\}$ & 9.100 & \multicolumn{2}{|c|}{$\mathrm{B}$} & 4.290 & $\mathrm{~B}$ \\
\hline$\{$ China, Thailand, Laos, Cambodia, Vietnam\} & \multicolumn{5}{|c|}{45.887} \\
\hline
\end{tabular}

Note that $A$ denotes the coalition value of Thailand, Cambodia and Vietnam and is equal to 19.938 , and $B$ denotes the coalition value of Thailand, Laos and Vietnam and is equal to 31.376.

Table 5: Fishery income in Cambodia and hydropower benefits for mainstream Laos in different coalition structures in billion USD $(c=4,000)$

\begin{tabular}{|c|c|c|}
\hline The coalition structures & Hydropower Laos & Fishery Cambodia \\
\hline$\{$ China $\},\{$ Thailand $,\{$ Laos $\},\{$ Cambodia $\},\{$ Vietnam $\}$ & 11.263 & 0.748 \\
\hline$\{$ China $\},\{$ Thailand $\},\{$ Laos, Cambodia, Vietnam $\}$ & 10.697 & 2.436 \\
\hline$\{$ China,$\{$ Vietnam,$\{$ Thailand, Laos, Cambodia $\}$ & 10.697 & 2.436 \\
\hline$\{$ China,$\{$ Thailand, Laos, Cambodia, Vietnam $\}$ & 10.697 & 2.436 \\
\hline$\{$ China $\},\{$ Laos $\},\{$ Thailand, Cambodia, Vietnam $\}$ & 11.263 & 0.748 \\
\hline$\{$ China,$\{$ Cambodia,,$\{$ Thailand, Laos, Vietnam $\}$ & 11.263 & 0.748 \\
\hline$\{$ China, Thailand, Laos, Cambodia, Vietnam $\}$ & 10.697 & 2.436 \\
\hline
\end{tabular}


Table 6: water use per season per sector in the disagreement scenario, in $\mathrm{km}^{3}$

\begin{tabular}{|c|c|c|c|c|c|}
\hline sectors and seasons & China & Thailand & Laos & Cambodia & Vietnam \\
\hline household, wet & 1.393 & 1.393 & 0.066 & 0.049 & 0.593 \\
\hline household, dry & 1.195 & 1.393 & 0.066 & 0.049 & 0.593 \\
\hline industry, wet & 1.382 & 1.382 & 0.085 & 0.017 & 1.533 \\
\hline industry, dry & 1.330 & 1.382 & 0.085 & 0.017 & 1.533 \\
\hline irrigation, dry & 12.705 & 18.644 & 3.366 & 1.766 & 15.550 \\
\hline water reservation & 0.000 & 8.333 & 80.211 & 136.230 & 0.000 \\
\hline
\end{tabular}

\section{Water use amount in the disagreement scenario}

The water use amount for each sector and season and also the water reservation from the wet to the dry season is reported Table 6 . Note that the huge water reservation amount in Cambodia can be explained by the existence of Tonle Sap Lake.

\section{References}

Ambec, S. and L. Ehlers (2008). Sharing a river among satiable agents. Games and Economic Behavior 64, 35-50.

Ambec, S. and Y. Sprumont (2002). Sharing a river. Journal of Economic Theory 10\%, $453-462$.

Baran, E., T. Jantunen, and C. C. Kieok (2007). Values of inland fisheries in the Mekong River Basin. Phnom Penh, Cambodia: WorldFish Center.

Binmore, K., A. Rubinstein, and A. Wolinsky (1986). The Nash bargaining solution in economic modeling. RAND Journal of Economics 17, 176-188.

Blankespoor, B., A. Basist, A. Dinar, S. Dinar, H. Houba, and N. Thomas (2014). Assessing the economic and political impacts of climate change on international river basins using surface wetness in the Zambezi and Mekong basins. Tinbergen 
Institute Discussion Paper. TI 2014-005/II.

Campbell, I. (2009). The Mekong: Biophysical Environment of an International River Basin. Amsterdam: Elsevier.

d'Aspremont, C., A. J. J. G. and J. Weymark (1983). On the stability of collusive price leadership. Canadian Journal of Economics 16, 17-25.

Dinar, A., S. Dinar, S. McCaffrey, and D. McKinney (2013). Bridges over water: understanding transboundary water conflict, negotiation and cooperation (2nd ed.). World Scientific.

Dinar, S. and A. Dinar (2003). Recent developments in the literature on conflict negotiation and cooperation over shared international fresh waters. Natural Resources Journal 43(4), 1217-1287.

Dinar, S., D. Katz, L. De Stefano, and B. Blankespoor (2015). Climate change, conflict and cooperation: global analysis of the effectiveness of international river treaties in addressing water variability. Political geography 45, 55-66.

Eyckmans, J. and M. Finus (2004). An almost ideal sharing scheme for coalitional games with externalities. Working Paper, Katholieke Universiteit Leuven.

FAO. Fishery statistical collections database. http://www.fao.org/fishery/statistics/globalcommodities-production/en. Accessed: 2015-05-20.

Gebreluel, G. (2014). Ethiopia's Grand Renaissance dam: Ending Africa's oldest geopolitical rivalry? The Washington Quarterly 37(2), 25-37.

Haddad, M. S. (2011). Capacity choice and water management in hydroelectricity systems. Energy Economics 33, 168-177.

Heijnen, P. and L. Dam (2015). Catastrophe and cooperation. Working Paper, University of Groningen.

Houba, H., K. H. Pham Do, and X. Zhu (2013). Saving a river: A joint management approach to the Mekong River Basin. Environmental and Development Economics 18, 93-109. 
Houba, H., G. van der Laan, and Y. Zeng (2014b). Asymmetric Nash solutions in the river sharing problem. Strategic Behavior and the Environment 4, 321-360.

ICEM (2009). MRC SEA for hydropower on the Mekong mainstream. International Center for Environment Management. Hanoi, Vietnam.

ICEM (2010). MRC Strategic Environmental Assessment (SEA) of hydropower on the Mekong mainstream. International Center for Environment Management. Hanoi, Vietnam.

IRENA (2012). Renewable energy technologies: Cost analysis series. Working Paper, International Renewable Energy Agency.

Jeuland, M. and D. Whittington (2014). Water resources planning under climate change: Assessing the robustness of real options for the Blue Nile. Water Resource Research 50(3), 2086-2107.

Just, R. and S. Netanyahu (1998). Conflict and cooperation on trans-boundary water resources. Boston/Dordrect/London: Kluwer Academic Publishers.

McCaffrey, S. (2001). The Law of International Watercourses. Oxford: Oxford University Press.

MRC (2010). State of the basin report. Mekong River Commission. Vientiane, Laos.

Nash, J. (1950). The bargaining problem. Econometrica 18, 155-162.

Olmstead, S. M. and H. Sigman (2014, July). Damming the commons: an empirical analysis of international cooperation and conflict in dam location.

Pham Do, K. H. and A. Dinar (2014). The role of issue linkage in managing noncooperative basins: The case of the Mekong. Natural Resource Modeling 27(4), $492-518$.

Poyry (2011). Feasibility study of Xayaburi hydroelectric power project - meteorological and hydrological study. Final Report, Poyry AG. Zurich, Switzerland.

Ringler, C., J. von Braun, and M. Rosegrant (2004). Water policy analysis for the Mekong River Basin. Water International 29, 30-42. 
Sigman, H. (2002). International spillovers and water quality in rivers: Do countries free ride? American Economic Review 92, 1152-1159.

Sothorn, K., C. Chhun, T. Vuthy, and S. Sovannarith (2011). Policy coherence in agricultural and rural development: Cambodia. Working paper. Phnom Penh: CDRI. the Economist (2016). The Mekong river: Damned if you do. print edition February 13 th.

Weikard, H.-P. (2009). Cartel stability under an optimal sharing rule. The Manchester School 77, 575-593.

Weikard, H.-P., M. Finus, and J.-C. Altamirano-Cabrera (2006). The impact of surplus sharing on the stability of international climate agreements. Oxford Economic Papers 58, 209-232.

World Bank. http://data.worldbank.org/indicator/NY.GDP.MKTP.CD. Accessed: 2015-06-01.

Ziv, G., E. Baran, S. Nam, I. Rodriguez-Iturbe, and S. A. Levin (2012). Trading-off fish biodiversity, food security, and hydropower in the Mekong River Basin. Proceedings of the National Academy of Science 109(15), 5609-5614. 